\title{
More Benefits From Endovascular Thrombectomy in Patients With Atrial Fibrillation?
}

\author{
Masatoshi Koga, MD, PhD
}

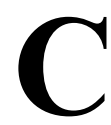
onsiderable changes in acute stroke management have occurred since evidence for the benefits of endovascular thrombectomy in acute ischemic stroke patients with major vessel occlusion within $6 \mathrm{~h}$ of onset was established in 2015.1-5 The number needed to treat with endovascular thrombectomy to reduce disability by at least 1 level on the modified Rankin Scale [mRS, which ranges from 0 (no symptoms) to 6 , with mRS 5 indicating severe disability and mRS 6 indicating death] was only $2.6^{6}$ The sooner endovascular thrombectomy is performed after stroke symptom onset, the better the functional outcomes that can be expected, according to a meta-analysis. ${ }^{7}$ Endovascular thrombectomy is the key component of acute stroke management and extensive efforts are underway to reduce delays to revascularization both in Japan and worldwide.

Atrial fibrillation (AF) is a major contributor to ischemic stroke. According to the Japan Standard Stroke Registry Study, cardioembolic stroke, mainly caused by AF, accounts for $28 \%$ of all ischemic strokes. Importantly, around 50\% of patients in Japanese reperfusion studies and large vessel occlusion (LVO) registries have AF (Table). ${ }^{\mathbf{8}, 9}$ These rates appear high as compared with those in other trials. ${ }^{1-5}$ One reason for this deviation may be the super-aging population in Japan. The rate of AF increases linearly after 50 years in the general population and the prevalence beyond 80 years old is $4.4 \%$ in men and $2.2 \%$ in women, and the estimated total number of patients with AF is approximately 0.9

\section{Article p 2647}

million in Japan. ${ }^{\mathbf{1 0}}$

In this issue of the Journal, Suda and colleagues ${ }^{11}$ report changes in anticoagulation, treatment, and functional outcomes among acute ischemic stroke patients with nonvalvular AF from 2011 to 2017 using a single-center prospective stroke registry. The study period was set between the year of approval of the first direct oral anticoagulant (DOAC) in Japan and 2 years after the establishment of endovascular thrombectomy within $6 \mathrm{~h}$ of stroke onset. They clearly show a steady increase in reperfusion therapy (intravenous thrombolysis (IVT), endovascular treatment (EVT) or IVT+EVT) over time. Particularly in patients with moderate-to-severe stroke (initial National Institutes of Health Stroke Scale $\geq 10$ ), EVT alone and IVT+EVT increased and unfavorable outcomes, including death at discharge, decreased during the study period. Multivariate logistic regression analyses revealed reperfusion therapy [odds ratio (OR), 5.5; 95\% confidence interval (CI), 2.3912.87] as independently and positively associated with good functional outcomes $(\mathrm{mRS} \leq 2)$ at discharge. IVT+EVT (OR, 0.13; 95\% CI, 0.0008-0.69) was independently and negatively associated with death. Because temporal trend data for acute stroke management are limited, this report could reflect current clinical performance in an EVT-capable comprehensive stroke center. Although this was an

\begin{tabular}{|c|c|c|c|c|c|c|}
\hline $\begin{array}{l}\text { Studies and } \\
\text { trials }\end{array}$ & Nation & $\begin{array}{c}\text { No. of } \\
\text { patients }\end{array}$ & Design & Treatment & $\begin{array}{c}\text { Mean age } \\
\text { enrolled (years) }\end{array}$ & $\begin{array}{l}\text { No. }(\%) \text { of } \\
\text { AF patients }\end{array}$ \\
\hline SAMURAI rt-PA & Japan & 600 & Registry & IVT & 72 & $258(43)$ \\
\hline J-MARS & Japan & 7,492 & Registry & IVT & 72 & $3,345(45)$ \\
\hline RESCUE Japan & Japan & 1,442 & Registry & IVT, EVT or None & 75.5 & $853(59)$ \\
\hline RESCUE2 Japan & Japan & $1,278^{*}$ & Registry & $\mathrm{EVT}^{\star *}$ & 74.7 & $658(51)$ \\
\hline MR CLEAN & Netherlands & 500 & Randomized trial & $\mathrm{EVT}^{\star * *}$ & 65.8 & $135(27)$ \\
\hline ESCAPE & Multiple nations & 316 & Randomized trial & $\mathrm{EVT}^{\star *}$ & 69.5 & $121(38)$ \\
\hline EXTEND-IA & Australia and New Zealand & 70 & Randomized trial & $\mathrm{EVT}^{\star *}$ & 69.4 & $23(33)$ \\
\hline SWIFT PRIME & United States & 196 & Randomized trial & $\mathrm{EVT}^{\star *}$ & 65.7 & $73(37)$ \\
\hline REVASCAT & Spain & 206 & Randomized trial & $\mathrm{EVT}^{\star \star}$ & 66.5 & $72(35)$ \\
\hline
\end{tabular}

*Only patients treated with EVT. **EVT mainly following IVT. AF, atrial fibrillation; EVT, endovascular treatment; IVT, intravenous thrombolysis.

The opinions expressed in this article are not necessarily those of the editors or of the Japanese Circulation Society.

Received August 16, 2018; accepted August 22, 2018; released online September 5, 2018

Department of Cerebrovascular Medicine, National Cerebral and Cardiovascular Center, Suita, Japan

Mailing address: Department of Cerebrovascular Medicine, National Cerebral and Cardiovascular Center, 5-7-1 Fujishirodai, Suita 565-8585, Japan. E-mail: koga@ncvc.go.jp

ISSN-1346-9843 All rights are reserved to the Japanese Circulation Society. For permissions, please e-mail: cj@j-circ.or.jp 
observational study, further increases in appropriate reperfusion therapy generate better clinical outcomes in ischemic stroke patients.

Ischemic stroke patients with AF show poorer outcomes (including death) than those without. ${ }^{12}$ Probably because of the abrupt occlusion of large vessels and insufficient collateral circulation, AF could cause large infarcts and severe neurological deficits. AF is also known as an independent and negative predictor of favorable outcome following IVT. Kimura et al reported early recanalization after IVT as less frequent in patients with AF. ${ }^{13}$ They suggested that patients with AF may have large or old thrombi that cannot be dissolved by IVT. According to a meta-analysis of IVT, AF was negatively associated with favorable outcome ( $\mathrm{mRS} \leq 2)(\mathrm{OR}, 0.51 ; 95 \% \mathrm{CI}, 0.35-0.75)$, and positively associated with symptomatic intracerebral hemorrhage (OR, 1.28; 95\% CI, 1.08-1.52) and death at 90 days (OR, 2.13; 95\% CI, 1.68-2.70). ${ }^{14}$ On the other hand, a meta-analysis of EVT revealed that favorable outcome $(\mathrm{mRS} \leq 2)$ at 90 days $(\mathrm{OR}, 2.40 ; 95 \% \mathrm{CI}, 1.81-3.19)$ was more frequent in patients with AF. ${ }^{15}$ Greater benefit could thus be expected from EVT for patients with AF as compared to those without.

This report also found that increased use of DOAC prior to ischemic events during the study period and patients with prior DOAC therapy were associated with milder neurological symptoms than those with warfarin or without anticoagulation. Data showing prior DOAC effects on neurological severity and clinical outcomes after ischemic stroke remain scarce. Because the number of patients with prior DOAC use $(n=57)$ was small in this study, further investigations of larger cohorts are needed to confirm this association.

Only a few years ago, IVT was the only effective reperfusion therapy for acute ischemic stroke patients with AF. Patients with LVO and AF can now be effectively treated by EVT+IVT or EVT alone. There still seems to be considerable room for increasing the number of treatable patients and improving delays to reperfusion therapy. Beyond the study results, several efforts and improvements in the preand in-hospital settings are needed to shorten the time to receipt of reperfusion therapy. Unfortunately, the authors did not provide the details of such performance. Continuous education of emergency medical services, physicians, nurses and co-medical staff, collaboration among these personnel, and feedback systems should be key factors in good acute stroke management. Stroke teams with physicians, nurses and co-medical staff are expected to improve these conditions.

\section{Conflict of Interest}

M.K. received lecture fees from Bayer Yakuhin, Ltd.

\section{References}

1. Berkhemer OA, Fransen PS, Beumer D, van den Berg LA, Lingsma HF, Yoo AJ, et al. A randomized trial of intraarterial treatment for acute ischemic stroke. $N$ Engl J Med 2015; 372: $11-20$.

2. Goyal M, Demchuk AM, Menon BK, Eesa M, Rempel JL, Thornton J, et al. Randomized assessment of rapid endovascular treatment of ischemic stroke. N Engl J Med 2015; 372: 10191030.

3. Jovin TG, Chamorro A, Cobo E, de Miquel MA, Molina CA, Rovira A, et al. Thrombectomy within 8 hours after symptom onset in ischemic stroke. N Engl J Med 2015; 372: 2296-2306.

4. Saver JL, Goyal M, Bonafe A, Diener HC, Levy EI, Pereira VM, et al. Stent-retriever thrombectomy after intravenous t-PA vs. t-PA alone in stroke. $N$ Engl J Med 2015; 372: 2285-2295.

5. Campbell BC, Mitchell PJ, Kleinig TJ, Dewey HM, Churilov L, Yassi N, et al. Endovascular therapy for ischemic stroke with perfusion-imaging selection. N Engl J Med 2015; 372: 1009-1018.

6. Goyal M, Menon BK, van Zwam WH, Dippel DW, Mitchell PJ, Demchuk AM, et al. Endovascular thrombectomy after large-vessel ischaemic stroke: A meta-analysis of individual patient data from five randomised trials. Lancet 2016; 387: $1723-$ 1731.

7. Saver JL, Goyal M, van der Lugt A, Menon BK, Majoie CB, Dippel DW, et al. Time to treatment with endovascular thrombectomy and outcomes from ischemic stroke: A meta-analysis. JAMA 2016; 316: 1279-1288.

8. Yoshimura S, Sakai N, Okada Y, Kitagawa K, Kimura K, Tanahashi N, et al. Efficacy of endovascular treatment for acute cerebral large-vessel occlusion: Analysis of nationwide prospective registry. $J$ Stroke Cerebrovasc Dis 2014; 23: 1183-1190.

9. Yoshimura S, Sakai N, Uchida K, Yamagami H, Ezura M, Okada $Y$, et al. Endovascular therapy in ischemic stroke with acute large-vessel occlusion: Recovery by Endovascular Salvage for Cerebral Ultra-Acute Embolism Japan Registry 2. $\mathrm{J} \mathrm{Am}$ Heart Assoc, doi:10.1161/JAHA.118.008796.

10. Inoue H, Fujiki A, Origasa H, Ogawa S, Okumura K, Kubota I, et al. Prevalence of atrial fibrillation in the general population of Japan: An analysis based on periodic health examination. Int $J$ Cardiol 2009; 137: 102-107.

11. Suda S, Sakamoto Y, Okubo S, Aoki J, Shimoyama T, Kanamaru T, et al. Anticoagulants, reperfusion therapy, and outcomes in ischemic stroke patients with non-valvular atrial fibrillation: A single-center, 6-year experience of 546 consecutive patients. Circ J 2018; 82: 2647-2654.

12. Heinsius T, Bogousslavsky J, Van Melle G. Large infarcts in the middle cerebral artery territory: Etiology and outcome patterns. Neurology 1998; 50: $341-350$.

13. Kimura K, Iguchi Y, Yamashita S, Shibazaki K, Kobayashi K, Inoue T. Atrial fibrillation as an independent predictor for no early recanalization after IV-t-PA in acute ischemic stroke. $J$ Neurol Sci 2008; 267: 57-61.

14. Yue R, Li D, Yu J, Li S, Ma Y, Huang S, et al. Atrial fibrillation is associated with poor outcomes in thrombolyzed patients with acute ischemic stroke: A systematic review and meta-analysis. Medicine (Baltimore) 2016; 95: $\mathrm{e} 3054$.

15. Zheng J, Shi L, Xu W, Zhao N, Liang F, Zhou J, et al. Impact of hyperlipidemia and atrial fibrillation on the efficacy of endovascular treatment for acute ischemic stroke: A meta-analysis. Oncotarget 2017; 8: 72972-72984. 